\title{
Risks of Mixtures of Oil Sands Contaminants to a Sensitive Mayfly Sentinel, Hexagenia
}

\author{
Julia Howland ${ }^{1,2, *(\mathbb{D})}$, Alexa Alexander ${ }^{1,2}$, Danielle Milani ${ }^{3}$, Kerry Peru ${ }^{4}(\mathbb{C})$ and Joseph Culp ${ }^{2,5}$ \\ 1 Biology, University of New Brunswick, Fredericton, NB E3B 5A3, Canada \\ 2 Environment and Climate Change Canada, Fredericton, NB E3B 5A3, Canada \\ Environment and Climate Change Canada, Burlington, ON L7S 1A1, Canada \\ Environment and Climate Change Canada, Saskatoon, SK S7N 3H5, Canada \\ 5 Cold Regions Research Center, Wilfrid Laurier University, Waterloo, ON N2L 3C5, Canada \\ * Correspondence: julia.howland@unb.ca
}

Received: 14 June 2019; Accepted: 22 July 2019; Published: 24 July 2019

\begin{abstract}
Tailings ponds in northeastern Alberta, Canada contain massive amounts of oil sands process water (OSPW) that cannot currently be released due to the toxicity of some components. Limited space and the need for reclamation of oil sands operation sites will necessitate the release of OSPW in the near future. Knowledge of the composition and toxicity of OSPW is lacking yet is crucial for both risk assessment and management planning. This study examines chronic toxicity of a mixture of OSPW components sodium naphthenate and naphthenic acid (NA) to nymphs of the mayfly Hexagenia spp. in control and polycyclic aromatic hydrocarbons (PAH)-spiked sediment treatments. The objective of this study was to determine whether the addition of the PAH-spiked sediment significantly contributed to or masked responses of these sensitive mayflies to mixtures of NA. Mean survival in nymphs exposed to NA and PAH-spiked sediment treatments was reduced by $48 \%$ compared to those exposed to the NA mixture alone. Lethal responses were observed in all of the PAH-spiked sediment treatments. However, within PAH-spiked and control sediment treatments, there was no significant difference in nymph survival due to NA concentration, indicating that changes in survivorship were predominantly a reflection of increased mortality associated with sediment PAHs and not to the NA mixture treatment. Sublethal effects on body segment ratios suggest that mayflies exposed to NA and PAH-spiked sediment, as well as those exposed to the highest NA concentration tested $(1 \mathrm{mg} / \mathrm{L})$ and control sediment, made developmental trade-offs in order to emerge faster and escape a stressful environment. These results reveal that the release of OSPW to the surrounding environment could cause a reduction in mayfly populations. Mayflies provide ecosystem services and are an important food source for higher trophic levels in both the aquatic and terrestrial communities.
\end{abstract}

Keywords: oil sands; contaminants; risk assessment; guidance

\section{Introduction}

Canada's oil sands in northeastern Alberta are among the largest crude oil deposits in the world [1]. Oil sands are a complex mixture of bitumen, sand, clay, and water that must be extracted and upgraded, often using hot water and proprietary surfactants [2]. The hot water extraction process used for Canada's oil sands requires the use of substantial amounts of freshwater, much of which is recycled but is often originally sourced from the Athabasca River or its tributaries. After use in extraction, the residual water contains a complex mixture of left-over bitumen, dissolved salts, trace metals, and organic compounds such as surfactants. The aqueous and solid components of this mixture, collectively referred to as tailings, is then pumped to on-site tailings ponds, where the solid components 
settle [2]. The aqueous portion, commonly referred to as oil sands process water (OSPW), can be recycled but tends to accumulate chemicals and become increasingly saline over time [3].

At present, there is a zero-discharge policy for oil sands tailings in Canada [2]. However, due to limited storage capacity, the treatment and release of treated OSPW to the surrounding environment may be required in the future $[4,5]$. Unfortunately, understanding of the composition and toxicity of OSPW is lacking, yet is crucial for both risk assessment and management planning [6]. OSPW varies between tailings ponds due to differences in mining practices, for example, the application of different surfactants such as metallic naphthenates [6]. Assessing risk is further challenged by the considerable uncertainty concerning the ecological effects of OSPW on aquatic environments, in part due to the complexity of these process water mixtures. There is a lack of environmental guidelines even for many of the more common chemicals used in the extraction process such as sodium naphthenate.

Naphthenic acids have been identified as important components of OSPW and high concentrations have been correlated with toxicity [7]. These carboxylic acids are the organic components of many common surfactants used in the extraction of oil from bitumen. Naphthenic acids are toxic to aquatic species and are of concern due to their solubility and widespread persistence in waterways [8,9]. In a prior study, mixtures of naphthenic acids and a common metallic surfactant, sodium naphthenate, were found to be acutely toxic to sensitive aquatic communities, and mayflies in particular [10]. This study further examines this trend by investigating the same naphthenic acid mixtures in addition to the presence of a suite of sediment-borne PAHs.

Polycyclic aromatic hydrocarbons (PAHs) are another common contaminant in the Athabasca oil sands region and the levels of the compounds have increased in the lower Athabasca watershed since the industry boom of the 1960s [11]. PAHs are known toxins to both fish and invertebrates [12]. Effects of naphthenic acid mixtures in combination with other contaminants present in OSPW are largely unknown but are assumed to be additively toxic $[13,14]$. Many tributaries of the lower Athabasca River are prone to slumping such that a significant influx of sediments and contaminants is not uncommon [15]. A recent study on PAH signatures in sediment found significant contributions of naphthalenes, phenanthrenes, fluoranthenes, pyrenes, as well as benzo(a)pyrenes in sediments from two tributaries of the lower Athabasca River [16]. These environmentally-relevant PAHs were among those examined in the sediment testing portion in this study.

The objective of this study was to explore the combined effects of mixtures of three overlapping types of contaminants commonly found in the oil sands region (naphthenic acids, sodium naphthenate, and 17 PAHs) for an environmentally-relevant aquatic insect species (mayfly nymphs). Various levels of naphthenic acid mixtures were tested on Hexagenia spp. mayflies both with and without the added stress of PAH-spiked sediment. Endpoints examined included a combination of toxicological (e.g., lethal) and functional (e.g., growth) responses. We hypothesized that co-exposure to aqueous naphthenic acid and sodium naphthenate mixtures and PAH-spiked sediments would be more toxic than either substance individually.

\section{Materials and Methods}

\subsection{Study Species}

Hexagenia spp. were chosen for this study because, in aquatic ecosystems, sediment can accumulate contaminants. Consequently, sensitive invertebrates such as burrowing mayflies are at higher risk of exposure to contaminants in both sediment and water, which has the potential to produce additive or even synergistic toxic effects [17]. Fertilized Hexagenia spp. eggs were collected in June 2017 from Lake St. Clair in Windsor, Ontario using the method of Hanes and Ciborowski [18]. Culturing protocols were adapted from methods of Fremling [19], Friesen [20], and Giberson and Rosenberg [21]. In brief, hatched nymphs were transferred to glass culture tanks held in the growth chambers at $22 \pm 3^{\circ} \mathrm{C}$ with a 16:8 light to dark cycle. Tanks contained approximately $5 \mathrm{~cm}$ of sediment topped with deionized water and all received constant aeration and feeding twice per week. See Howland et al. [10] for more detail. 


\subsection{Establishment of Treatments}

In this study, two sediment treatments (control, PAH-spiked) were examined in a 21 day chronic exposure experiment (10/4/18 to 3/5/18). In each sediment treatment, 5 concentrations of a 10:1 mixture of naphthenic acids and sodium naphthenate were reproduced (see Table 1 for concentrations). Each treatment contained 3 replicates which received ten late instar Hexagenia spp. nymphs (average total length of $6.7 \mathrm{~mm}$ ). Mixture concentrations were prepared using a commercial preparation (lot \# DLODE of NO397, TCI America, Portland, OR) that had previously been chemically characterized as similar to tailings pond water and acutely toxic to mayflies with a $48 \mathrm{~h} \mathrm{LC50} \mathrm{of} 0.43 \pm 0.34 \mathrm{mg}$ sodium naphthenate/L (4.3 mg naphthenic acid/L) (see Howland et al. [10]). The aqueous 10:1 naphthenic acid/ sodium naphthenate solution will be referred to as the NA mixture hereafter. Sediment treatments included a PAH-spiked sediment from Sigma Aldrich (CAS\# CRM104-50G, lot\# LRAB5247) (Table 2), and an unspiked natural (control) sediment of similar $<1 \mathrm{~mm}$ particle size collected from Magaguadavic Lake, New Brunswick ( $45^{\circ} 47.62^{\prime} \mathrm{N} \times 67^{\circ} 13.48^{\prime} \mathrm{W}$, see [9]). Wet sediment was finely sieved to $1 \mathrm{~mm}$ and $30 \mathrm{~g}$ of control (unspiked), wet sediment was added to each replicate $300 \mathrm{~mL}$ beaker (Kimble, KIMAX ${ }^{\mathrm{TM}}$ tall form beakers, Fisher Sci., Hampton, NH, USA). For PAH treatments, $10 \mathrm{~g}$ of PAH-spiked sediment was also added. Each replicate then received $0.15 \mathrm{~g}$ of ground NutraFin Bug Bites fish food (Rolf C. Hagen Inc., Baie d'Urfé, QC, Canada). Beakers were then filled to the $300 \mathrm{~mL}$ mark with the appropriate NA solution and gently mixed to ensure integration of NA and ground NutraFin into the sediment pore water. Plastic lids with a hole drilled in the center for aeration were placed on top and sealed to prevent evaporation (Figure 1). The beakers were stored in Percival ${ }^{\circledR}$ (Percival Scientific, Perry, IA, USA) environmental chambers at $22 \pm 3^{\circ} \mathrm{C}$ with a light-dark cycle of $16: 8 \mathrm{~h}$. Over the course of the 21-day experiment, each replicate was fed $0.15 \mathrm{~g}$ of NutraFin twice per week and at which time solutions were also statically renewed. Constant aeration was provided using an air pump, tubing, and glass pipettes fed through plastic lids sealed to the top of each beaker (Figure 1). The beakers were allowed to settle for $24 \mathrm{~h}$ before mayflies were added to the treatments.

Table 1. Comparison of the actual (mean \pm standard error [SE]) versus nominal concentrations of 10:1 mixture of total naphthenic acids and sodium naphthenate as determined by scanning synchronous fluorescence spectroscopy analysis. All solutions were prepared using a serial dilution of stock concentrations of a commercial source representative of oil sands process water (OSPW).

\begin{tabular}{|c|c|c|c|c|c|c|c|c|c|c|}
\hline OSPW & & Naph & nenic $\mathrm{A}$ & ids & & & Sodiun & Naphtl & nate & \\
\hline$\%$ & $\begin{array}{c}\text { Nominal } \\
(\mathrm{mg} / \mathrm{L})\end{array}$ & $\begin{array}{l}\text { Actual } \\
(\mathrm{mg} / \mathrm{L})\end{array}$ & $\pm \mathrm{SE}$ & $\begin{array}{c}\text { Actual } \\
(\mu \mathrm{M})\end{array}$ & $\pm \mathrm{SE}$ & $\begin{array}{c}\text { Nominal } \\
(\mathrm{mg} / \mathrm{L})\end{array}$ & $\begin{array}{l}\text { Actual } \\
(\mathrm{mg} / \mathrm{L})\end{array}$ & $\pm \mathrm{SE}$ & $\begin{array}{c}\text { Actual } \\
(\mu \mathrm{M})\end{array}$ & $\pm \mathrm{SE}$ \\
\hline 0.01 & 0.01 & 0.01 & $<0.01$ & 0.059 & $<0.059$ & 0.001 & $<0.01$ & $<0.01$ & $<0.052$ & $<0.052$ \\
\hline 0.1 & 0.1 & 0.17 & $<0.01$ & 0.999 & $<0.059$ & 0.01 & 0.01 & $<0.01$ & 0.052 & $<0.052$ \\
\hline 1 & 1 & 1.45 & 0.02 & 8.517 & 0.117 & 0.1 & 0.12 & $<0.01$ & 0.624 & $<0.052$ \\
\hline 14 & 10 & 14.47 & 0.25 & 84.991 & 1.468 & 1 & 1.16 & 0.02 & 6.034 & 0.104 \\
\hline
\end{tabular}

\subsection{Chemical Analyses}

Comparison of the commercial NA compound with OSPW samples from Syncrude and Suncor tailings ponds revealed analogous compositions. The chemical analyses are described in detail elsewhere (see Howland et al. [10]). In brief, NA mixture concentrations were prepared using a commercial 10:1 preparation of naphthenic acids and sodium naphthenate. Two approaches were used to analyze and characterize the composition of the NA commercial preparation. First, the analysis was conducted using the scanning synchronous fluorescence spectroscopy (SFS) method of Kavanaugh et al. [22] on an Aquamate spectrophotometer with deuterium and tungsten lamp attachments (Thermo Spectronic, Rochester, NY), which revealed a similar fluorescence signature between our commercial NA mixture and the tailings pond samples. Second, to fully characterize the naphthenic acids from the commercial preparation, samples from the same lot number of the commercially prepared stock were also analyzed at the Environment and Climate Change Canada laboratory in Saskatoon, SK by 
high resolution mass spectrometry (Orbitrap) with electrospray ionization (see Howland et al. [10]). This analysis revealed that the naphthenic acid composition in the commercial samples were $99.8 \% \mathrm{O}_{2}$ species and that the range of carbon numbers ( 8 to $22, \mathrm{z}=1$ to $\mathrm{z}=6 \mathrm{O}_{2} \mathrm{DBE}$ ) found in our commercial NA mixture was also typical of oil sands process water extracts.

Table 2. Comparison of estimated actual (mean \pm standard error [SE]) concentrations of 17 polycyclic aromatic hydrocarbons (PAH) present in spiked sediment tests used in this study versus field levels reported by Droppo et al. [16].

\begin{tabular}{|c|c|c|c|c|}
\hline РАН & This Study & & & Droppo Study [16] \\
\hline & AVG (ng/mg) & \pm & SE & AVG (ng/mg) \\
\hline Acenaphthene & 0.174 & & 0.009 & \\
\hline Acenaphthylene & 0.118 & & 0.006 & \\
\hline Anthracene & 0.16 & & 0.008 & \\
\hline Benzo(a)anthracene & 0.034 & & 0.002 & \\
\hline Benzo(a)pyrene & 0.08 & & 0.004 & 0.3322 \\
\hline Benzo(b)fluoranthene & 0.102 & & 0.005 & \\
\hline Benzo $(b+k)$ fluoranthene & 0.052 & & 0.008 & \\
\hline Benzo(g,h,i)perylene & 0.044 & & 0.002 & \\
\hline Benzo(k)fluoranthene & 0.063 & & 0.003 & \\
\hline Chrysene & 0.046 & & 0.002 & \\
\hline Dibenzo(a,h)anthracene & 0.025 & & 0.001 & \\
\hline Fluoranthene & 0.108 & & 0.005 & 0.2714 \\
\hline Fluorene & 0.075 & & 0.004 & \\
\hline Indeno(1,2,3-cd) pyrene & 0.076 & & 0.004 & \\
\hline Naphthalene & 0.094 & & 0.005 & 0.4072 \\
\hline Phenanthrene & 0.116 & & 0.006 & 0.077 \\
\hline Pyrene & 0.064 & & 0.003 & 1.7156 \\
\hline
\end{tabular}

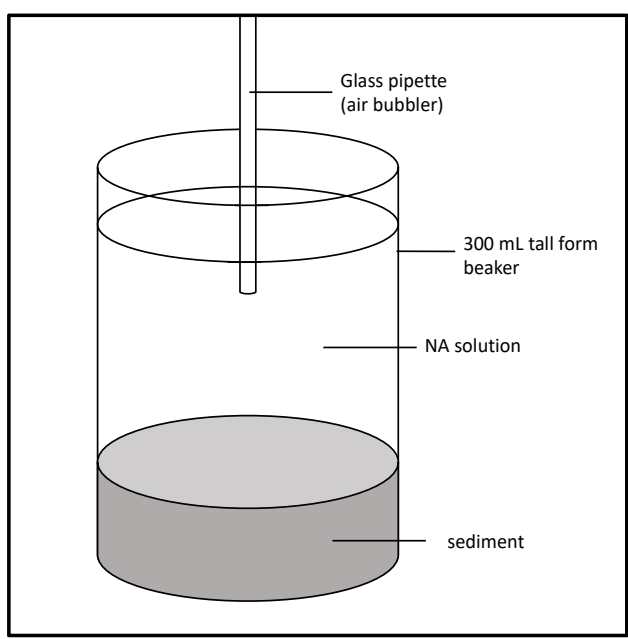

(a)

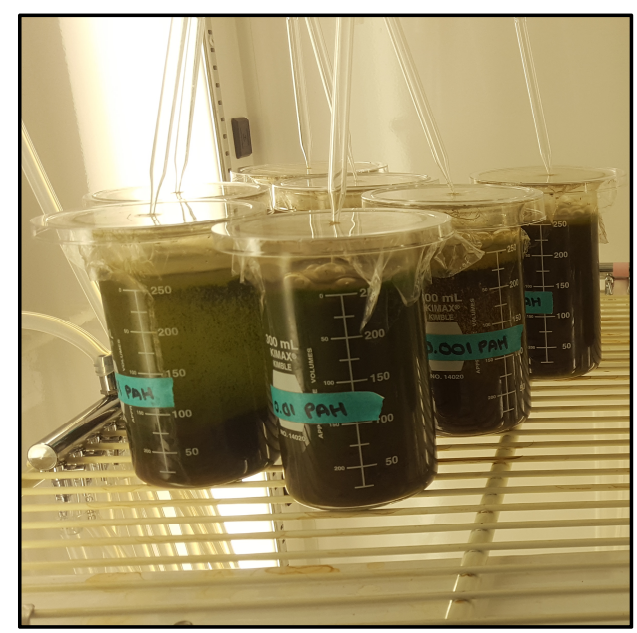

(b)

Figure 1. Laboratory setup for 21 day exposure to NA mixture treatments $(0,0.001,0.1,1 \mathrm{mg} / \mathrm{L})$ and control sediment or polycyclic aromatic hydrocarbons (PAH)-spiked sediment: (a) individual replicate and (b) treatment set up in an environmental chamber.

PAH-spiked sediments were prepared using a certified reference material. Sediments were weighed on an OHAUS ${ }^{\circledR}$ Navigator ${ }^{\mathrm{TM}}$ scale to the closest $0.01 \mathrm{~g}$ and then added to the un-spiked sediment as described previously. These reference sediments are certified for round-robin testing of laboratories seeking International Organization for Standardization (ISO) 8100, 8270, 8310 or equivalent certification. Sediment quantity in each beaker was unfortunately insufficient for individual analytical testing, however, a series of reference materials and $300 \mathrm{~g}$ composite samples prepared using the 
same methods as those in the test beakers were also sent to a local commercial laboratory with ISO certification for validation (RPC Fredericton). All results from the whole and composite samples were found to be within acceptable ISO certification limits. Actual concentrations for these standard materials are reported in Table 2.

\subsection{Biological Response Variables}

At the end of the 21-day experiment, replicate beakers were dismantled, and the contents collected. Sediment was sieved to remove nymphs and the number surviving from each beaker was recorded. Surviving mayfly nymphs were then collected and preserved in $95 \%$ ethanol for subsequent measurement and weighing-decomposition made this impossible for the mortalities. Total body length, thorax length, thorax width, head length, and head width were measured using the Auto-Montage ${ }^{\circledR}$ imaging system (Syncroscopy, Synoptics Inc., Frederick, ND, USA) with a Leica@ digital camera and dissecting microscope (Leica@ Microsystems Ltd., Cambridge, UK). Wing pad development was noted and each nymph was also subsequently weighed. Finally, nymphs were dried for $48 \mathrm{~h}$ in a $60^{\circ} \mathrm{C}$ drying oven and re-weighed to determine dry weight. At the onset of the experiment, a subsample of the same-sized nymphs was also collected, measured, and weighed in order to determine the size at the onset of the experiment (time zero).

\subsection{Statistical Analyses}

A split-plot ANOVA design [23] was used to analyze the data. The predictor variables were NA concentration and sediment type (blocking variable) and the response variables were the nymph measurements (e.g., length, wet weight). A principal component analysis (PCA) was used to visualize and independently evaluate the relative importance of naphthenic acids, sodium naphthenate, and the 17 PAHs tested on Hexagenia body size measurements. PCA is a multivariate technique that can be used to confirm the strength of relationships among different factors (principal components). Nymph survival between sediment types was compared using Welch's t-test, as the assumption of homogeneity of variances was not met when tested by Levene's Test for Homogeneity of Variance $(p=0.008)$. Nymph survival between NA solution treatments was compared using one-way ANOVA. Shapiro-Wilks test was used to test normality. All tests were conducted using R (v. 3.1).

\section{Results}

\subsection{Lethal Responses to Treatment}

Mayfly survival in the combined NA solution and PAH-spiked sediment treatments was reduced by $48 \%$, on average, compared to responses in nymphs exposed to the NA mixture alone $(t=3.28$, $d f=14.44, p=0.005$ ) (Figure 2). Lethal responses to the treatments were observed in all NA mixture concentrations within the PAH-spiked sediment treatments. However, within PAH-spiked as well as within the control sediment treatments, there was no significant difference in nymph survival due to NA mixture concentration (PAH-spiked sediment: $p=0.36, F=1.22, F$-crit $=4.07$; control sediment: $p$ $=0.70, F=0.49, F$-crit $=4.07)$. Therefore, changes in survivorship were predominantly a reflection of increased mortality associated with sediment PAHs and not to the aqueous NA mixture (Figure S1).

\subsection{Sublethal Responses to Treatment}

The PCA biplot highlighted the two distinct groupings dependent on exposure to PAH or control sediment that cumulatively accounted for $91.3 \%$ of the variation in the nymph body size dataset (Figure 3). Factor 1 explained $66.3 \%$ of the variation (x-axis, Figure 3 ), was strongly positively correlated to the presence of PAHs in the spiked sediment. Factor 2 explained $25.0 \%$ of the variation and was modestly positively correlated to NA mixture concentration and strongly negatively correlated to the body size measurements (Figure 3). 


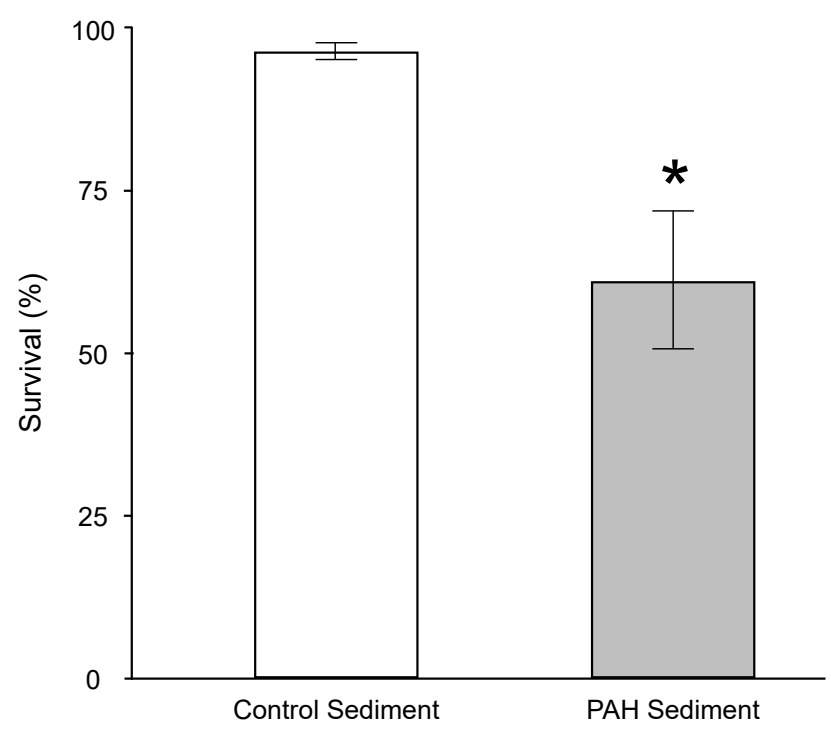

Figure 2. Mean nymph survival with standard error, grouped by sediment treatment. Survival was significantly lower in the PAH-spiked sediment treatment group in comparison to the control sediment treatment group (denoted by “*”).

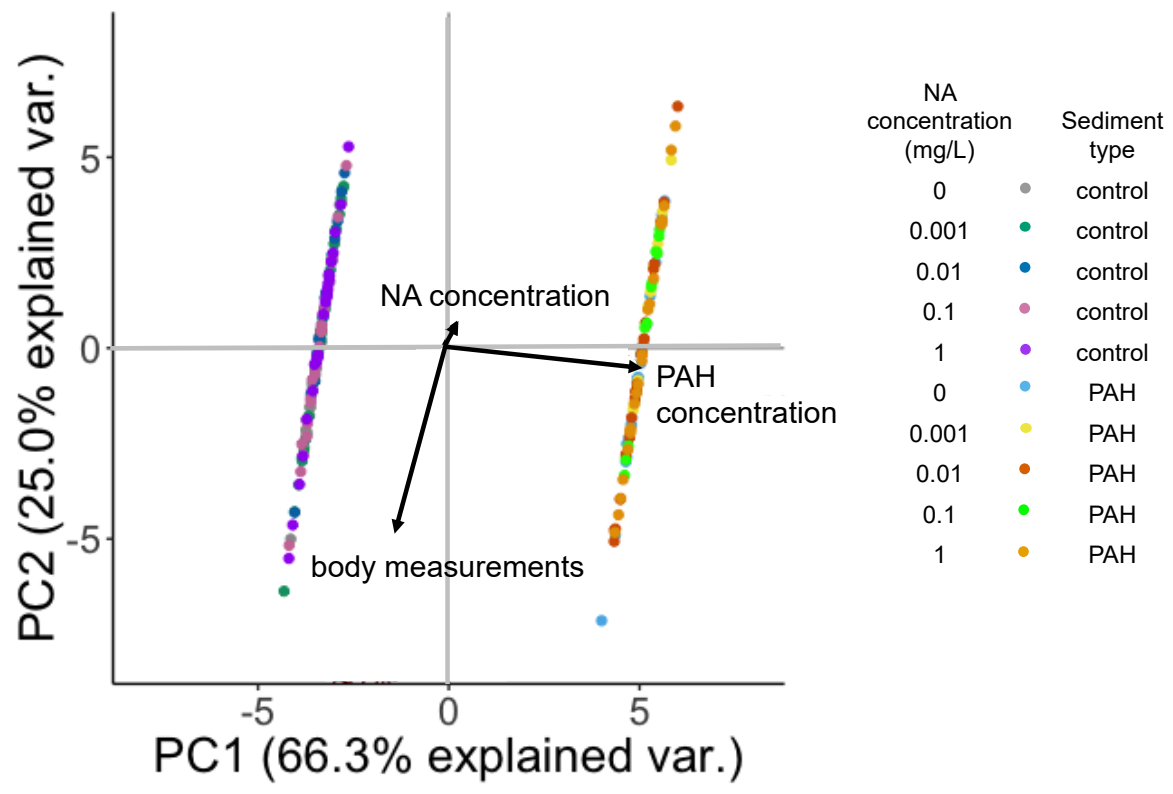

Figure 3. Principal components analysis (PCA) explaining $91.3 \%(66.3+25 \% \mathrm{EV})$ of the total variation in the body size measurements of Hexagenia nymphs exposed to an NA mixture gradient $(0-1 \mathrm{mg} / \mathrm{L})$ and sediment with or without PAHs (see Table 2 for PAH concentrations).

Mayflies exposed to the NA mixture and control sediments exhibited significant $(p<0.05)$ growth over the course of the 21-day experiment with the exception of head length (Figure 4). Thorax length $(43.1 \% \pm 1.9 \mathrm{SE}$; Figure $4 \mathrm{a})$, thorax width $(25.5 \% \pm 2.0 \mathrm{SE}$; Figure $4 \mathrm{~b})$, and wet weight $(105.5 \% \pm$ $9.8 \mathrm{SE}$; Figure $4 \mathrm{~d})$ were uniformly larger $(34.7 \% \pm 1.7 \mathrm{SE})$ irrespective of NA treatment by the end of the experiment. In contrast, the head length was reduced in all NA treatments compared to the control $(p<0.001)$. Head length was particularly reduced in the 0.001 and $0.1 \mathrm{mg} / \mathrm{L} \mathrm{NA}$ treatments, which were $13.3 \%$ and $17.1 \%$ lower than the control head lengths respectively. In contrast, treatments with PAH-spiked sediments significantly $(p<0.05)$ reduced the size of some body segments in the mayflies (Figure 4$)$. For instance, thorax length $(p=0.004)$ and thorax width $(p=0.031)$ were both 
reduced $7.7 \%$ and $10.2 \%$, respectively, in mayfly survivors exposed to PAH-spiked sediment treatments compared to the control (Figure 4a,b). Although not significant at the $p<0.05$ level, wet weight of nymphs in PAH-spiked sediment treatments were also reduced by $14.2 \%$ ( $p=0.103$, Figure $4 \mathrm{~d}$ ), while the total length was reduced by $3.8 \%$ compared to the controls ( $p=0.0942$, see Figure S2).

a)

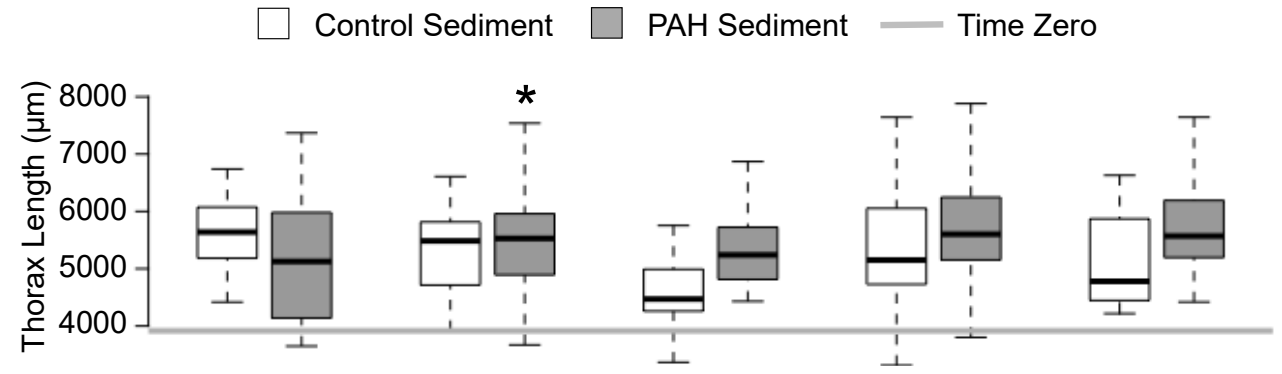

b)

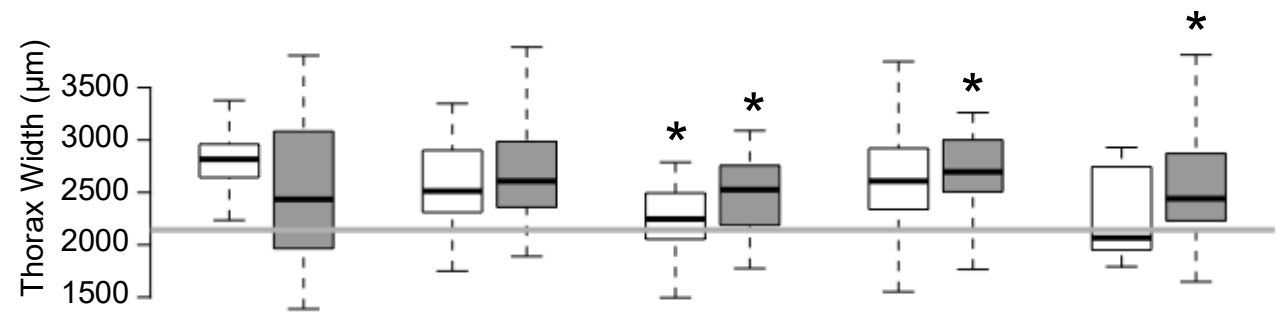

c)

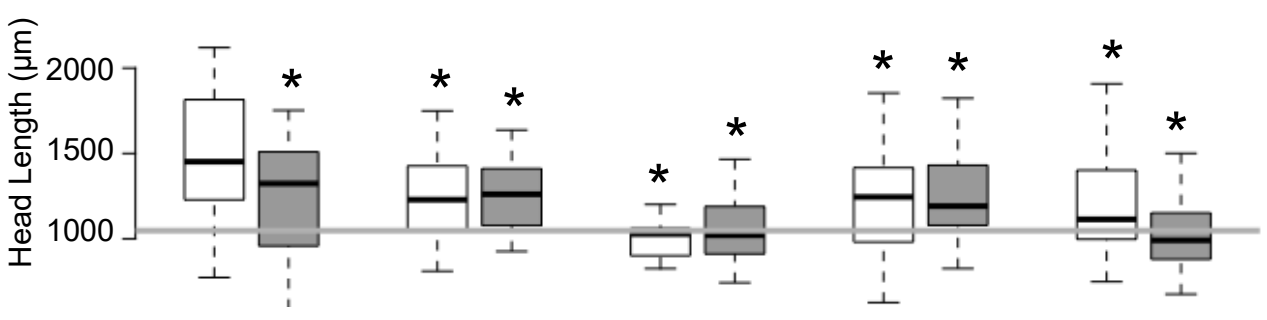

d)

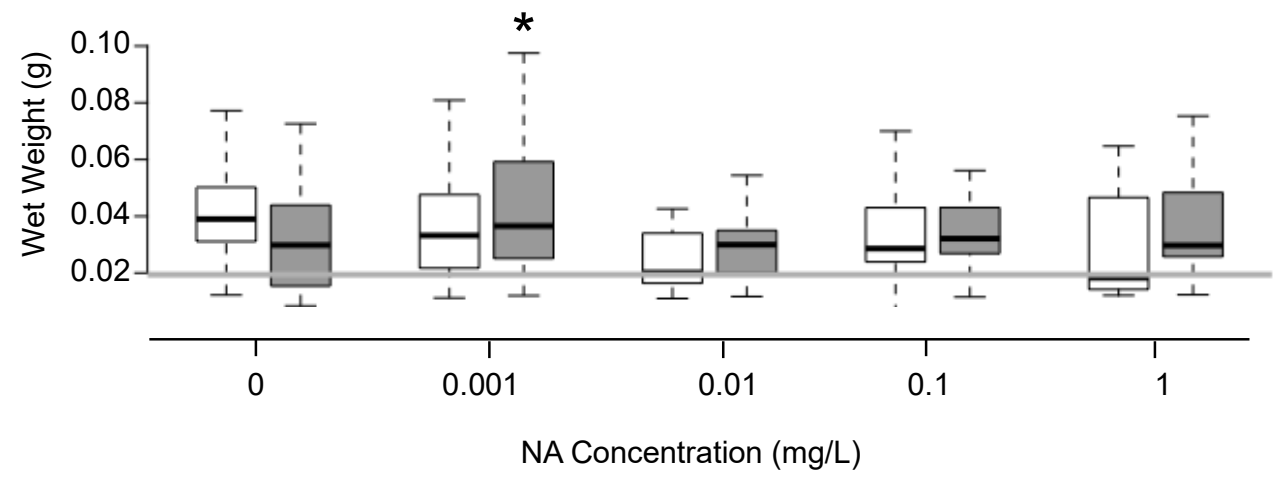

Figure 4. Boxplot comparison of sublethal changes (showing the maximum, $75^{\text {th }}$ percentile, median, $25^{\text {th }}$ percentile and minimum) in thorax length (a), thorax width (b), head length (c), and wet weight (d) in Hexagenia mayfly nymphs exposed to an NA mixture in either control (white, left) or PAH-spiked sediment treatments for a 21-day period. Significant differences from the control $(0 \mathrm{mg} / \mathrm{L} \mathrm{NA}$ and control sediment, far left bar) are indicated by "*" and time zero measurements are indicated by grey horizontal lines for comparison.

Further, in PAH-spiked sediments, surviving mayflies typically grew $33.7 \% \pm 2.6$ in thorax length over the course of the 21-day experiment compared to time zero (Figure 4a). However, growth pattern responses within PAH-spiked sediment treatments were NA mixture concentration dependent (Figure 4). Notably, the thorax (Figure 4a), head length (Figure 4c), and wet weight (Figure 4d) of the mayflies were unchanged $(p>0.05)$ compared to time zero in the combined PAH-spiked sediment and 
lowest concentration of NA mixture tested $(0.001 \mathrm{mg} / \mathrm{L})$. A similar pattern was also observed for the mayflies in the combined PAH-spiked sediment and NA treatments at the $0.1 \mathrm{mg} / \mathrm{L}$ level for the thorax width (Figure $4 \mathrm{~b}$ ) and wet weight, which was particularly variable (e.g., $C V=72.3 \%$; Figure $4 \mathrm{~d}$ ).

As above, the total length to thorax length ratios also significantly differed due to the sediment treatment type but seldom responded to changes in NA concentration (Figure 5). In particular, total length to thorax length ratios were significantly different $(p=0.0006)$ between the PAH-spiked sediment and control sediment groups. Total length was favored (ratios $<0.3$ ) in the mayflies in the control sediment and thorax length was favored (ratios $>0.3$ ) in mayflies in the PAH-spiked sediment (see Figure S3). Thorax length favored ratios were also apparent $(p=0.072)$ in the highest concentration $(1 \mathrm{mg} / \mathrm{L})$ NA mixture control sediment treatment compared to the $0 \mathrm{mg} / \mathrm{L} \mathrm{NA}$ mixture control sediment treatment (Figure 5).

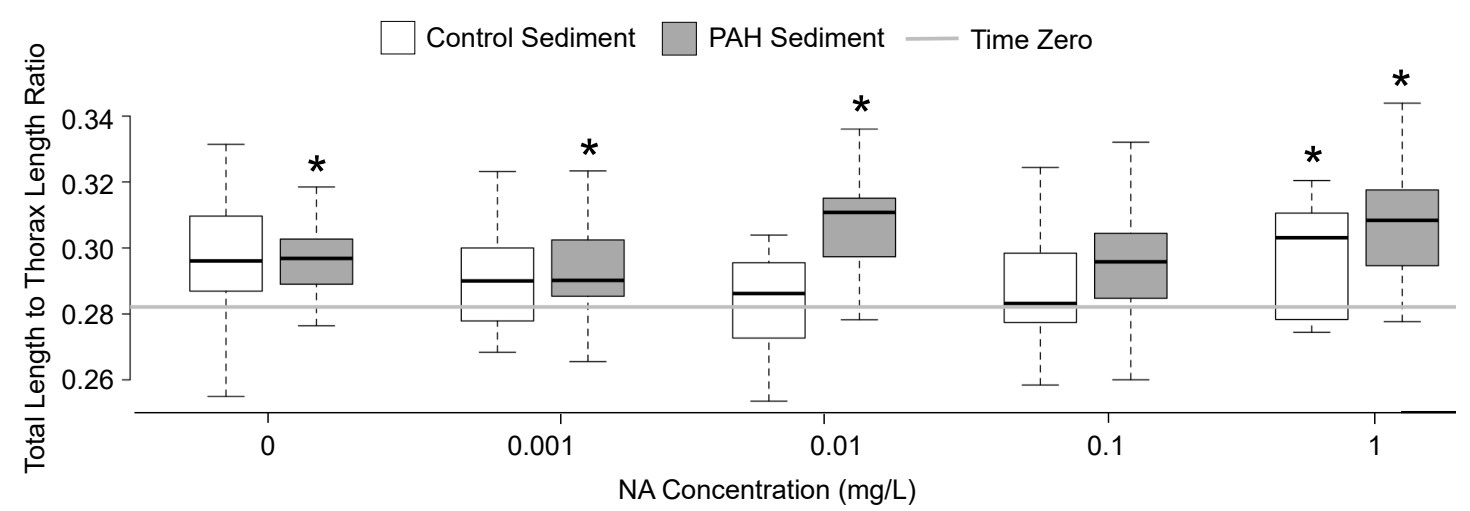

Figure 5. Boxplot comparison of total length to thorax length ratios (showing the maximum, $75^{\text {th }}$ percentile, median, $25^{\text {th }}$ percentile, and minimum) in total length to thorax length ratio in Hexagenia mayfly nymphs exposed to an NA mixture in either control (white, left) or PAH-spiked sediment treatments for a 21-day period. Significant differences from the control $(0 \mathrm{mg} / \mathrm{L} \mathrm{NA}$ and control sediment, far left bar) are indicated by "** and the time zero measurements are indicated by a grey horizontal line for comparison.

\section{Discussion}

In the event of a planned release of OSPW into the Athabasca River or other freshwater rivers, mayflies and other aquatic macroinvertebrates may be chronically exposed to low concentrations of tailings contaminants. Chronic exposure to even very low concentrations of toxins can cause both lethal and sublethal effects in mayflies [24,25]. Sublethal effects on growth and development in response to stress can have an impact on the reproductive success of adult mayflies [26,27]. This study documents both lethal and sublethal response of Hexagenia nymphs due to exposure to environmentally-relevant concentrations of aqueous NA mixtures with control versus PAH spiked-sediments.

\subsection{Lethal Responses to Treatment}

The reduction in mayfly survival was predominantly due to exposure to the PAH-spiked sediment treatment (Figures 2 and 3). This effect is of concern because there has been a striking increase in PAH levels in the Athabasca area sediment since the oil boom of the 1970s $[11,28,29]$. Total sediment PAH concentrations of over $6000 \mathrm{ng} / \mathrm{g}$ have been measured in the Athabasca region, with higher concentrations associated with samples closer to development sites [28]. Levels of PAHs tested in this study were 50 times lower than concentrations measured near oil sands developments (Table 1), and significant effects were observed even at these levels. However, it is possible that local populations of Hexagenia have adapted tolerance to PAHs. 
In this study, no differences in survival were detected between control sediment treatments due to the addition of NA treatment. However, it is worth noting that the greatest concentration of the NA mixture tested was but $1 \mathrm{mg} / \mathrm{L}$, which is two orders of magnitude lower than concentrations reported in tailings ponds $(128 \mathrm{mg} / \mathrm{L}$, [4]). At present, even the most effective methods of removing naphthenic acids, such as constructed wetlands, remove only up to $80 \%$ of the types of substances tested in this study [30]. Thus, the concentrations of NA could easily remain in the 8-24 mg/L range. In a previous study, acute toxicity of the same mixture of NA was also tested and found that NA could be acutely toxic with a $48 \mathrm{~h}$ LC50 of $0.43 \pm 0.34 \mathrm{mg}$ sodium naphthenate/L ( $4.3 \mathrm{mg}$ naphthenic acid/L) [10]. It seems plausible that even a 100-fold dilution of concentrations of naphthenic acids and their metallic salts in contemporary tailings ponds could be toxic to sensitive aquatic insects like mayflies. The combination of highly toxic responses to environmentally-relevant concentrations of PAH-contaminated sediment irrespective of NA concentration suggests that even low concentrations of NA could be toxic to aquatic communities when faced with cumulative stressors.

Responses to sediments with trace metal concentrations are, at present, under studied and may offer further insights. Trace metal levels in the Athabasca region are naturally elevated and can be further amplified by industrial activity [31,32]. These effects paired with other stressors such as oil production emissions, and/or natural occurring PAHs and hydrocarbons, as well as climate change [10], could have a devastating effect on Hexagenia populations. Aquatic macroinvertebrates such as Hexagenia provide significant contributions to ecosystem services in freshwater rivers that could create a cascading effect on the ecosystem if populations are diminished [33]. Aquatic invertebrates provide prey for aquatic predators and are also consumed by terrestrial predators such as birds, reptiles, and insects. Adult insects also transport aquatic material to terrestrial habitats upon emerging, which is an important energy transfer between ecosystems [34].

\subsection{Sublethal Responses to Treatment}

In control sediment treatments, a significant reduction in head length was observed in all NA mixture treatments in comparison to the $0 \mathrm{mg} / \mathrm{L}$ control. This indicates that developmental trade-offs were made in order to reduce time to emergence in response to NA exposure. Although differences were not significant, the average wet weight displayed a similar pattern, excluding the $0.001 \mathrm{mg} / \mathrm{L}$ treatment, which was slightly larger than the $0 \mathrm{mg} / \mathrm{L}$ treatment. This may be due to a common sublethal stress response called 'hormesis' - a biphasic dose response to toxins that represents an apparently favorable response to low dose treatment [35]. Rather, the ability for organisms to compensate for exposure may be an important indicator of plasticity to these stressors and may also be useful for estimating the no observable effect concentration.

There were no significant differences in thorax width among treatments and there was less growth over time in comparison to thorax length. This again indicates that resources were used to develop the thorax and wings to expedite emergence, rather than reach an optimal body size for reproduction. Similar patterns have also been reported in other studies conducted by Scrimgeour et al. [27] and Peckarsky et al. [36] who have tended to find that mayflies can escape a stressful aquatic environment by favoring development over size. Similarly, in the PAH-spiked sediment treatments, there was an interesting pattern among thorax width, head length, and wet weight responses: Mayflies exposed to $0.001 \mathrm{mg} / \mathrm{L} \mathrm{NA}$ did not show significant growth compared to time zero, while almost all other treatments did - those that did not still grew, but there was more variation leading to a non-significant result. This again supports the theory that development trade-offs are made in order to escape exposure to stressors by emerging earlier.

All NA mixture treatments in the PAH-spiked sediment group, as well as the highest concentration NA mixture within the control sediment group favored a longer thorax in relation to the total length. This again indicates advancing thorax and wing development as a trade-off for reaching larger size overall in response to stress. 
When analyzing sublethal effects, it is imperative to remember that we are only measuring responses of the surviving nymphs. Therefore, it is possible that the survivors in the higher NA mixture concentration treatments were larger and/or more fit than the nymphs that died in those treatments. In the treatments with PAH-spiked sediment, there was a lot of variation in survival, indicating possible differences in size and/or fitness between individuals within the population.

\section{Conclusions}

In aquatic systems such as the Athabasca River, it is important to consider other possible stressors when working on a management plan for OSPW release. Sediment and nutrient load, flow velocity and volume, pollution from emissions and groundwater, and the presence of other contaminants can all affect community responses. Survival in treatments with both NA mixture and PAH-spiked sediment was reduced by $48 \%$. This highlights the importance of considering additive effects from multiple stressors. Sublethal effects also indicate body size trade-offs to enable earlier emergence. While small changes may seem insignificant, long term effects on adult fecundity and/or survival could be detrimental to the ecosystem. In colder climates such as northern Alberta, Hexagenia spends from two to four years in their aquatic stage [37], making them susceptible to multiple exposures depending on the proposed OSPW release plan. Release of OSPW to the surrounding environment is not advised until current technologies can further reduce toxicity.

\section{Future Directions}

Continued study is warranted-a chronic mesocosm study that exposes a field-collected community to low concentrations of NA or diluted OSPW would prove useful to help determine long term effects of OSPW release on community structure. Use of field-collected invertebrates from the Athabasca region would also account for differences in sensitivity among populations. In the event of a planned OSPW release, there would also likely be other contaminants as well as suspended sediment depending on the treatment process. All of these factors should be taken into account when creating a management plan for the release of OSPW in the Athabasca region.

Supplementary Materials: Are available online at http://www.mdpi.com/1424-2818/11/8/118/s1, Figure S1: Comparison of mean survival in Hexagenia, Figure S2: Comparison of sublethal changes in total length in Hexagenia, Figure S3: Representation of total length-favored and thorax length-favored body segments in Hexagenia.

Author Contributions: Conceptualization, A.A., J.C. and J.H.; methodology, A.A., D.M., K.P., and J.H.; validation, A.A., J.C., and J.H.; formal analysis, J.H. and A.A.; investigation, J.H., A.A. and K.P.; resources A.A., D.M., and K.P; data curation, J.H.; writing-original draft preparation, J.H.; writing-review and editing, J.H. and A.A.; visualization, J.H.; supervision, A.A.; project administration, A.A. and J.H.; funding acquisition, A.A. and J.C.

Funding: This research was funded by Environment and Climate Change a-base funding (A.A. and J.C.) and an NSERC Discovery (RGPIN-2018-03868) to A.A.

Acknowledgments: Our thanks to Donna Giberson for her insights on Hexagenia culturing and Dave Hryn for technical assistance with the experimental setup.

Conflicts of Interest: The authors declare no conflict of interest. The funders had no role in the design of the study; in the collection, analyses, or interpretation of data; in the writing of the manuscript, or in the decision to publish the results.

\section{References}

1. CAPP (Canadian Association of Petroleum Producers). Available online: http://www.capp.ca/canadian-oiland-natural-gas/oil-sands/what-are-oil-sands (accessed on 13 June 2019).

2. Natural Resources Canada: Oil Sands Processes. Available online: https://www.nrcan.gc.ca/energy/oil-sands/ 58539 (accessed on 24 April 2017).

3. Schramm, L.L.; Stasiuk, E.N.; MacKinnon, M. Surfactants in Athabasca Oil Sands Slurry Conditioning, Flotation, Recovery, and Tailings Processes. In Surfactants Fundamentals and Applications in the Petroleum Industry; Schramm, L.L., Ed.; Cambridge University Press: Cambridge, UK, 2000; pp. 365-430. 
4. Allen, E.W. Process water treatment in Canada's oil sands Industry: I. Target pollutants and treatment objectives. J. Environ. Eng. Sci. 2008, 7, 123-138. [CrossRef]

5. Brown, L.D.; Ulrich, A.C. Oil sands naphthenic acids: A review of properties, measurement, and treatment. Chemosphere 2015, 127, 276-290. [CrossRef] [PubMed]

6. Mahaffey, A.; Dubé, M.; Mahaffey, A. Review of the composition and toxicity of oil sands process affected water. Environ. Rev. 2017, 25, 97-114. [CrossRef]

7. Van Den Heuvel, M.R. In Response: An academic perspective on the release of oil sands process-affected water. Environ. Toxicol. Chem. 2015, 34, 2682-2684. [CrossRef] [PubMed]

8. Mackinnon, M.D.; Boerger, H. Description of two treatment methods for detoxifying oil sands tailings pond water. Water Qual. Res. J. Can. 1986, 21, 496-512. [CrossRef]

9. Frank, R.A.; Roy, J.W.; Bickerton, G.; Rowland, S.J.; Headley, J.V.; Scarlett, A.G.; Hewitt, M.L. Profiling oil sands mixtures from industrial developments and natural groundwaters for source identification. Environ. Sci. Technol. 2014, 48, 2660-2670. [CrossRef] [PubMed]

10. Howland, J.R.; Alexander, A.C.; Milani, D.; Culp, J.M.; Peru, K.M. Effects of oil sands process water mixtures on the mayfly Hexagenia and field-collected aquatic macroinvertebrate communities. Ecotoxicology 2019, 28, 658-668. [CrossRef] [PubMed]

11. Kurek, J.; Kirk, J.L.; Muir, D.C.; Wang, X.; Evans, M.S.; Smol, J.P. Legacy of a half century of Athabasca oil sands development recorded by lake ecosystems. Proc. Natl. Acad. Sci. USA 2012, 110, 1761-1766. [CrossRef] [PubMed]

12. De Hoop, L.; Schipper, A.M.; Huijbregts, M.A.J.; Hendriks, A.J.; Viaene, K.P.J.; De Laender, F. Time-varying effects of aromatic oil constituents on the survival of aquatic species: Deviations between model estimates and observations. Environ. Toxicol. Chem. 2017, 36, 128-136. [CrossRef] [PubMed]

13. Gauthier, P.T.; Norwood, W.P.; Prepas, E.E.; Pyle, G.G. Metal-PAH mixtures in the aquatic environment: A review of co-toxic mechanisms leading to more-than-additive outcomes. Aquat. Toxicol. 2014, 154, 253-269. [CrossRef]

14. Alharbi, H.A.; Morandi, G.; Giesy, J.P.; Wiseman, S.B. Effect of oil sands process-affected water on toxicity of retene to early life-stages of Japanese medaka (Oryzias latipes). Aquat. Toxicol. 2016, 176, 1-9. [CrossRef] [PubMed]

15. Ferrel, K.R.A.; Patsinghasanee, S.; Kimura, I.; Shimizu, Y. Coupled model of bank erosion and meander evolution for cohesive riverbanks. Geosciences 2018, 8, 359. [CrossRef]

16. Droppo, I.G.; di Cenzo, P.; Parrott, J.; Power, J. The Alberta oil sands eroded bitumen sediment transitional journey: Influence on sediment transport dynamics, PAH signatures and toxicological effect. Sci. Total Environ. 2019, 677, 718-731. [CrossRef] [PubMed]

17. Baun, A.; Hartmann, N.B.; Grieger, K.; Kusk, K.O. Ecotoxicity of engineered nanoparticles to aquatic invertebrates: A brief review and recommendations for future toxicity testing. Ecotoxicology 2008, 17, 387-395. [CrossRef] [PubMed]

18. Hanes, E.C.; Ciborowski, J.J.H. Effects of density and food limitation on size variation and mortality of larval Hexagenia rigida (Ephemeroptera: Ephemeridae). Can. J. Zool. 1992, 70, 1824-1832. [CrossRef]

19. Fremling, C.R.; Mauck, W.L. Methods for Using Nymphs of Burrowing Mayflies (Ephemeroptera, Hexagenia) as Toxicity Test Organisms. In Aquatic Invertebrate Bioassays; Buikema, A.L., Jr., Cairns, J., Jr., Eds.; ASTM STP 715; American Society for Testing and Materials: Philadelphia, PA, USA, 1980; pp. 81-97.

20. Friesen, M.K. Manual for the Culture of Selected Freshwater Invertebrates; Lawrence, S.G., Ed.; Canadian Special Publications of Fisheries and Aquatic Sciences; Department of Fisheries and Oceans: Winnipeg, MB, Canada, 1981; Volume 54, pp. 127-142.

21. Giberson, D.J.; Rosenberg, D.M. Effects of temperature, food quantity, and nymphal rearing density on life-history traits of a northern population of Hexagenia (Ephemeroptera: Ephemeridae). J. N. Am. Benthol. Soc. 1992, 11, 181-193. [CrossRef]

22. Kavanaugh, R.J.; Burnison, B.K.; Frank, R.A.; Solomon, K.R.; Van Der Kraak, G. Detecting oil sands process-affected waters in the Alberta oil sands region using synchronous fluorescence spectroscopy. Chemosphere 2009, 76, 120-126. [CrossRef]

23. Winer, B.J.; Brown, D.R.; Michels, K.M. Statistical Principles in Experimental Design; McGraw-Hill: New York, NY, USA, 1991. 
24. Lowell, R.B.; Culp, J.M.; Wrona, F.J. Stimulation of increased short-term growth and development of mayflies by pulp mill effluent. Environ. Toxicol. Chem. 1995, 14, 1529-1541. [CrossRef]

25. Alexander, A.C.; Heard, K.S.; Culp, J.M. Emergent body size of mayfly survivors. Freshw. Biol. 2008, 53, 171-180. [CrossRef]

26. Mckee, D.; Atkinson, D. The influence of climate change scenarios on populations of the mayfly Cloeon dipterum. Hydrobiologia 2000, 441, 55-62. Available online: https://link-springer-com.proxy.hil.unb.ca/ content/pdf/10.1023\%2FA\%3A1017595223819.pdf (accessed on 23 July 2019). [CrossRef]

27. Scrimgeour, G.J.; Cash, K.J.; Culp, J.M. Size-dependent flight initiation by a lotic mayfly in response to a predatory fish. Freshw. Biol. 1997, 37, 91-98. [CrossRef]

28. Evans, M.; Davies, M.; Janzen, K.; Muir, D.; Hazewinkel, R.; Kirk, J.; De Boer, D. PAH distributions in sediments in the oil sands monitoring area and western Lake Athabasca: Concentration, composition and diagnostic ratios. Environ. Pollut. 2016, 213, 671-687. [CrossRef] [PubMed]

29. Raine, J.C.; Turcotte, D.; Romanowski, L.; Parrott, J.L. Oil sands tailings pond sediment toxicity to early life stages of northern pike (Esox lucius). Sci. Total Environ. 2017, 664, 567-575. [CrossRef] [PubMed]

30. Ajaero, C.; Peru, K.M.; Simair, M.; Friesen, V.; O'Sullivan, G.; Hughes, S.A.; McMartin, D.W.; Headley, J.V. Fate and behavior of oil sands naphthenic acids in a pilot-scale treatment wetland as characterized by negative-ion electrospray ionization Orbitrap mass spectrometry. Sci. Total Environ. 2018, 631-632, 829-839. [CrossRef] [PubMed]

31. Headley, J.V.; Crosley, B.; Conly, F.M.; Quagraine, E.K. The characterization and distribution of inorganic chemicals in tributary waters of the Lower Athabasca River, Oilsands Region, Canada. J. Environ. Sci. Health 2005, 40, 1-27. [CrossRef] [PubMed]

32. Baker, L.F.; Ciborowski, J.J.H.; MacKinnon, M.D. Petroleum coke and soft tailings sediment in constructed wetlands may contribute to the uptake of trace metals by algae and aquatic invertebrates. Sci. Total Environ. 2012, 414, 177-186. [CrossRef]

33. Collier, K.J.; Probert, P.K.; Jeffries, M. Conservation of aquatic invertebrates: Concerns, challenges and conundrums. Aquat. Conserv. Mar. Freshw. Ecosyst. 2016, 26, 817-837. [CrossRef]

34. Thorp, J.H. Chapter 4-Functional Relationships of Freshwater Invertebrates; Thorp, J.H., Rogers, D.C., Eds.; Academic Press: Boston, MA, USA, 2015; pp. 65-82. [CrossRef]

35. Stebbing, A.R.D. Hormesis-The stimulation of growth by low levels of inhibitors. Sci. Total Environ. 1982, 22, 213-234. [CrossRef]

36. Peckarsky, B.L.; Taylor, B.W.; Mcintosh, A.R.; Mcpeek, M.A.; Lytle, D.A. Variation in Mayfly Size at Metamorphosis as a Developmental Response to Risk of. Source. Ecology 2001, 82, 740-757. Available online: https://www-jstor-org.proxy.hil.unb.ca/stable/pdf/2680193.pdf?refreqid= excelsior\%3Ad5e86ade5ad420abbccfc85d077b02ab (accessed on 23 July 2019). [CrossRef]

37. Giberson, D.J.; Rosenberg, D.M. Life histories of burrowing mayflies (Hexagenia limbata and H. rigida, Ephemeroptera: Ephemeridae) in a Northern Canadian reservoir. Freshw. Biol. 1994, 32, 501-551. [CrossRef]

(C) 2019 by the authors. Licensee MDPI, Basel, Switzerland. This article is an open access article distributed under the terms and conditions of the Creative Commons Attribution (CC BY) license (http://creativecommons.org/licenses/by/4.0/). 